\title{
MT4-MMP and EGFR expression levels are key biomarkers for breast cancer patient response to chemotherapy and erlotinib
}

\author{
Cassandre Yip ${ }^{1}$, Pierre Foidart ${ }^{1,2,3}$, Joan Somja ${ }^{4}$, Alice Truong ${ }^{1}$, Mehdi Lienard ${ }^{1}$, Emilie Feyereisen ${ }^{1}$,
} Hélène Schroeder ${ }^{2}$, Stéphanie Gofflot ${ }^{5}$, Anne-Françoise Donneau ${ }^{6}$, Joëlle Collignon ${ }^{2}$, Philippe Delvenne ${ }^{4}$, Nor Eddine Sounni ${ }^{1}$, Guy Jerusalem ${ }^{2,3,7}$ and Agnès Noël ${ }^{\star, 1,7}$

${ }^{1}$ Laboratory of Tumor and Developmental Biology, Groupe Interdisciplinaire de Génoprotéomique Appliqué-Cancer (GIGACancer), University of Liège, Liège 4000, Belgium; ${ }^{2}$ Department of Medical Oncology, University Hospital of Liège (CHU), Liège 4000, Belgium; ${ }^{3}$ Faculty of Medicine, University of Liège, Liège 4000, Belgium; ${ }^{4}$ Laboratory of Experimental Pathology, GIGACancer, University of Liège, Liège 4000, Belgium; ${ }^{5}$ Biobank (Biothèque Universitaire de Liège), University of Liège, Liège 4000, Belgium and ${ }^{6}$ Department of Biostatistics, University of Liège, 4000 Liège, Belgium

Background: Triple-negative breast cancers (TNBC) are heterogeneous cancers with poor prognosis. We aimed to determine the clinical relevance of membrane type-4 matrix metalloproteinase (MT4-MMP), a membrane type matrix metalloproteinase that interacts with epidermal growth factor receptor (EGFR) overexpressed in $>50 \%$ of TNBC.

Methods: We conducted a retrospective immunohistochemical analysis on human TNBC samples $(n=81)$ and validated our findings in in vitro and in vivo assays.

Results: Membrane type-4 matrix metalloproteinase and EGFR are produced in $72.5 \%$ of TNBC samples, whereas those proteins are faintly produced by healthy tissues. Unexpectedly, tumour relapse after chemotherapy was reduced in samples highly positive for MT4-MMP. Mechanistically, this is ascribed to a higher sensitivity of MT4-MMP-producing cells to alkylating or intercalating chemotherapeutic agents, as assessed in vitro. In sharp contrast, MT4-MMP expression did not affect tumour cell sensitivity to paclitaxel that interferes with protease trafficking. Importantly, MT4-MMP expression sensitised cancer cells to erlotinib, a tyrosine kinase EGFR inhibitor. In a pre-clinical model, the growth of MT4-MMP overexpressing xenografts, but not of control ones, was reduced by epirubicin or erlotinib. The combination of suboptimal drug doses blocked drastically the growth of MT4-MMPproducing tumours.

Conclusions: We demonstrate that MT4-MMP defines a sub-population of TNBC sensitive to a combination of DNA-targeting chemotherapeutic agents and anti-EGFR drugs.

Breast cancer is a highly prevalent cancer in women around the world (Torre et al, 2015). According to gene expression, six main intrinsic molecular subtypes of breast cancers are known: luminal A (HER2 negative), luminal B (triple-positive tumours), human epidermal growth factor receptor 2 (HER2) enriched, basal-like or/ and triple-negative breast cancer, normal breast-like group and claudin low (Perou et al, 2000; Sorlie et al, 2001; Carey et al, 2006; Herschkowitz et al, 2007). Triple-negative breast cancers (TNBC)

*Correspondence: Professor A Noël; E-mail: agnes.noel@ulg.ac.be

${ }^{7}$ Co-senior authors.

Received 22 December 2016; accepted 5 January 2017; published online 14 February 2017

(C) 2017 Cancer Research UK. All rights reserved 0007-0920/17 
representing $15 \%$ of breast cancers, are defined by the lack of expression of three receptors: oestrogen receptor, progesterone receptor and HER2. Triple-negative breast cancers are closely associated to basal-like breast cancers characterised by the expression of basal cytokeratin (CK) 5/6, CK14 and CK17. Bertucci et al (2008) reported that $71 \%$ of TNBC are found to be basal-like, whereas $77 \%$ of basal-like cancers are triple-negative. Triple-negative breast cancers are associated with aggressive features and poor clinical outcomes without efficient hormonal or targeted treatment options. Patients diagnosed with TNBC have a higher risk of relapse within 5 years than patients treated for other breast cancer subtypes (Bauer et al, 2007). Epidermal growth factor receptor (EGFR) is overexpressed in $>50 \%$ of TNBC (Carey et al, 2010). Importantly, the rate of mutation for this receptor in breast cancer is low (10\%) and is found mainly in Asian populations (Teng et al, 2011). Unfortunately, anti-EGFR-targeted therapy using antibodies (cetuximab; Carey et al, 2012; Baselga et al, 2013) or tyrosine kinase inhibitors (TKI; erlotinib, dasatinib) (Finn et al, 2011; Layman et al, 2013) in combination with chemotherapies were globally disappointing in clinical trials of TNBC (Yadav et al, 2014). Some clinical activity has been observed with immunotherapy (Nanda et al, 2016) and many clinical trials are ongoing in this field (Collignon et al, 2016) but no immunotherapy agent is currently approved for TNBC treatment. Therefore, the development of new strategies targeting TNBC or biomarker for a better patient stratification for conventional or targeted treatments is crucially needed.

We have recently identified the membrane type- 4 matrix metalloproteinase (MT4-MMP or MMP17) as a new EGFR partner (Paye et al, 2014). Membrane type- 4 matrix metalloproteinase belongs to the family of MT MMP that are tethered to the cell membrane through a trans-membrane domain (MT1-MMP, MT2-MMP, MT3-MMP and MT5-MMP) or a glycosylphosphatidylinositol anchor (MT4-MMP and MT6-MMP). Although the involvement of MMPs in cancer progression is well recognised and documented (Kessenbrock et al, 2010; Noel et al, 2012), only a few clinical and experimental studies report on MT4-MMP roles in cancer. Among the MMP family, MT4-MMP displays unique features and contributes to different steps of cancer progression through proteolytic and non-proteolytic functions (Chabottaux et al, 2006, 2009; Host et al, 2012; Paye et al, 2014). Membrane type- 4 matrix metalloproteinase internalisation and recycling rely on a unique CLIC/GEEK pathway dependent on cdc42 (Truong et al, 2016). In an experimental setting, MT4-MMP overexpression stimulated tumour growth, angiogenesis and lung metastases (Chabottaux et al, 2006, 2009; Paye et al, 2014). The MT4-MMP impact on haematogenous metastatic dissemination is related to its capacity to remodel blood vasculature in a proteolytic-dependent manner (Host et al, 2012). In line with these findings, MT4-MMP has also been reported to play a significant role in hypoxia-mediated metastasis and to be an important prognostic indicator in patients with head and neck or gastric cancer (Huang et al, 2009; Wang et al, 2015). Beyond promoting cell invasiveness, MT4-MMP overexpression also endows TNBC cells with a higher proliferation rate (Paye et al, 2014). Indeed, in a non-proteolytic manner, MT4-MMP interferes with the EGFR pathway and promotes EGFR activation in response to its ligands.

In this study, we investigated the clinical relevance of MT4MMP/EGFR axis by immunohistochemical (IHC) analyses and found that MT4-MMP and EGFR expressions were enhanced in $>70 \%$ of human TNBC tissues. We also established an unprecedented link between high MT4-MMP expression and high progression-free survival (PFS) in TNBC patients. We demonstrate that MT4-MMP plays a key role in tumour response to alkylating and intercalating chemotherapeutic drugs, but not to drug targeting microtubules. This novel concept is supported by in vitro and in vivo studies. Importantly, MT4-MMP expression sensitises tumours to a combination of chemotherapeutic and targeted antiEGFR (erlotinib) drugs.

\section{MATERIALS AND METHODS}

Immunohistochemistry and analysis of samples. Human TNBC cancer samples $(n=81)$ and normal breast tissue $(n=24)$ issued from mammary reduction were provided by the Biobank of the University Hospital of Liège (University of Liège, Belgium). The specimen collection and the distribution of human samples to researchers follow the rules imposed by the current legislation and the recommendations of the institutional review board (Comite d'éthique Hospitalo-Facultaire Universitaire de Liège), which approved this study. Human samples were formalin (4\%) fixed and paraffin embedded. The immunostainings of MT4-MMP and EGFR were performed on adjacent slides. For MT4-MMP immunohistochemistry, tumour sections $(6 \mu \mathrm{m}$ thick) were incubated in citrate buffer (DAKO S2031, Santa Clara, CA, USA) for $1 \mathrm{~h}$ at $80^{\circ} \mathrm{C}$. Endogenous peroxidases were subsequently blocked by $3 \% \mathrm{H}_{2} \mathrm{O}_{2} / \mathrm{H}_{2} \mathrm{O}$ for $20 \mathrm{~min}$, and non specific binding was prevented by incubation in $\mathrm{PBS} / 10 \%$ bovine serum albumin (Fraction V, Acros Organics, Fair Lawn, NJ, USA) for $1 \mathrm{~h}$. Slides were first incubated overnight at $4{ }^{\circ} \mathrm{C}$ with a rabbit polyclonal antihuman-MT4-MMP antibody (1/500; AB39028; Abcam, Cambridge, USA) and then with a HRP-conjugated anti-rabbit secondary antibody (Envision System-Labeled Polymer-HRP, $\mathrm{DAKO}, \mathrm{K} 4003)$, for $30 \mathrm{~min}$, at room temperature. For staining, 3-3' diaminobenzidine hydrochloride (DAKO, K3468) was incubated for $3 \mathrm{~min}$. Slides were finally counterstained with haematoxylin and mounted with Eukitt medium for microscope observation. For EGFR staining, antigen retrieval was performed with EDTA buffer. Slides were incubated with a rabbit monoclonal anti-EGFR antibody (5B7; 790-4347, Ventana Medical Systems, Roche, Indianapolis, IN, USA) for $32 \mathrm{~min}$, and signal amplification was achieved by using an amplification kit (760-080, Ventana Medical Systems, Roche) in a series automated slide strainer (Discovery XT, Ventana Medical Systems, Roche). Finally, sections were incubated with universal secondary antibody (760-4205, Ventana Medical Systems, Roche) for $32 \mathrm{~min}$ and signal was detected with DAB Map detection kit (760-124, Ventana Medical Systems, Roche). Counterstaining was performed with haematoxylin II (790-2208, Ventana Medical Systems, Roche). The specificity of MT4-MMP antibody has been tested on xenografts of human MDA-MB-231 cell line expressing or not MT4-MMP. The anti-EGFR antibody is currently used by anatomo-pathologists in clinical routine. Omission of the first antibody served as negative control.

The IHC results for EGFR and MT4-MMP were recorded as the percentage of breast cancer cell number showing a positive staining. The percentage of breast cancer cells expressing MT4MMP or EGFR was determined by a pathologist. Ki67 positivity was quantified as the percentage of positive nuclear staining of tumour cells. A cut off of $20 \%$ was used for assessing the active proliferation (Huang et al, 2013). Cytokeratin 5/6 staining was considered positive when $>10 \%$ tumour cells were labelled (Gazinska et al, 2013).

Cell culture. Human TNBC cells (MDA-MB-231) were purchased from the American Type Culture Collection (ATCC, Manassas, VA, USA). Cells were grown in DMEM supplemented with $10 \%$ FBS, L-glutamine $\left(2 \mathrm{mmol}^{-1}\right)$, penicillin $\left(100 \mathrm{U} \mathrm{ml}^{-1}\right)$ and streptomycin $\left(100 \mathrm{mg} \mathrm{ml}^{-1}\right)$, at $37^{\circ} \mathrm{C}$, in a $5 \% \quad \mathrm{CO}_{2}$ humid atmosphere. All culture reagents were purchased from Invitrogen (Carlsbad, CA, USA). MDA-MB-231 cells were stably transfected 
A
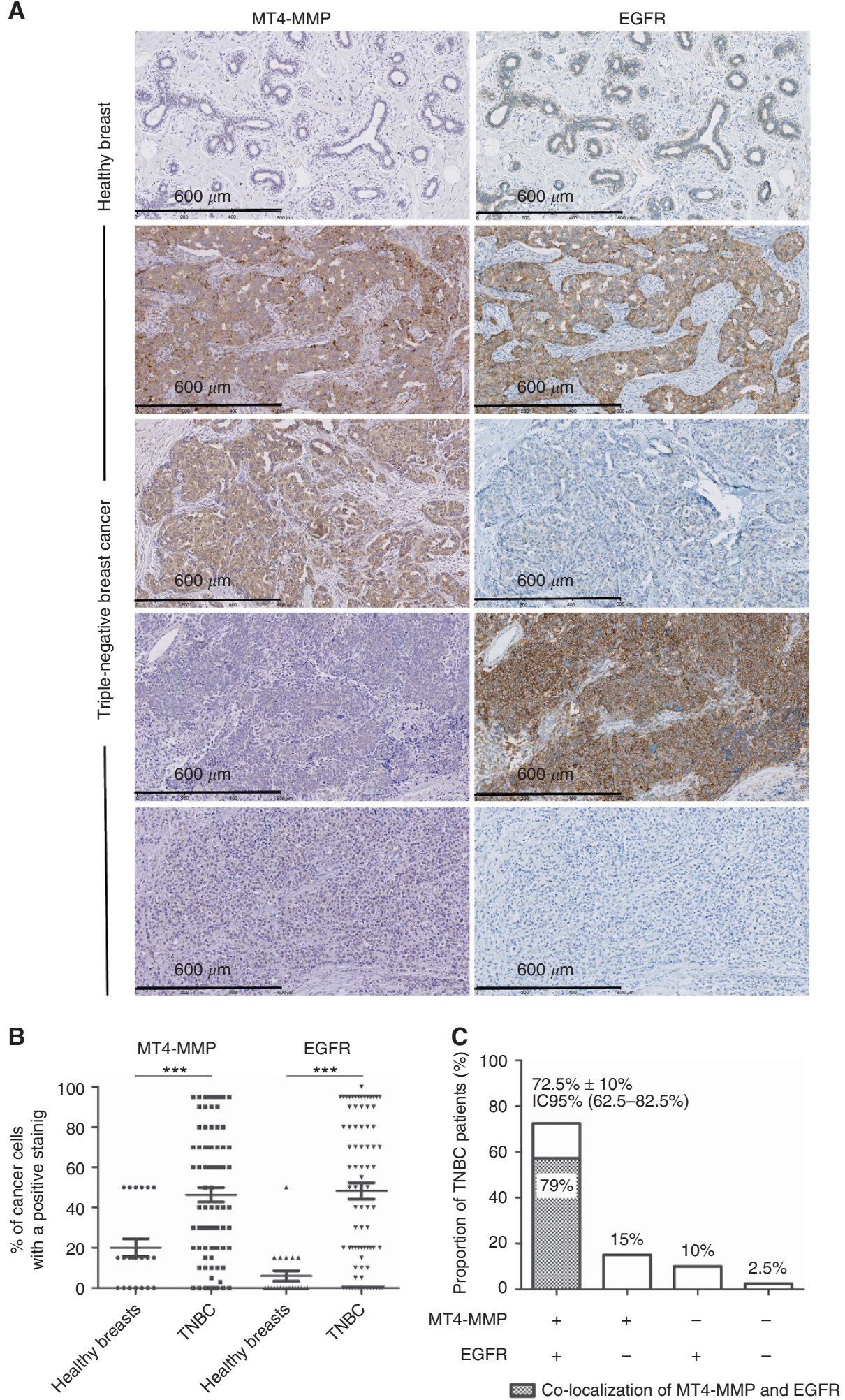

Figure 1. Immunohistochemical detection of MT4-MMP and EGFR in healthy breast tissues $(n=24)$ and TNBC samples $(n=81)$. (A) Representative immunostainings of MT4-MMP and EGFR in healthy breast and TNBC samples. (B) Distribution of the percentage of cancer cells with a positive MT4-MMP or EGFR staining in healthy breasts and TNBC. (C) Proportion of patients with TNBC presenting a double immunostaining (MT4-MMP + /EGFR +), a single staining of MT4-MMP or EGFR (MT4-MMP + /EGFR- or MT4-MMP-/EGFR +) and a negative staining (MT4-MMP-/EGFR-). The proportion of patients with a co-localisation of MT4-MMP and EGFR is also represented inside the histogram by the crosshatching area. $\star \star \star P<0.001$.

by electroporation with pcDNA3-neo vector, either empty (control plasmid, CTRL) or containing the active human full-length MT4-MMP cDNA (Chabottaux et al, 2009) tagged or not by a FLAG peptide
(DYKDDDDK) after Pro319 (Host et al, 2012). Stable transfectants were cultured in medium containing $500 \mu \mathrm{g} \mathrm{ml}^{-1}$ of G418 (Life Technologies, Thermo Fisher Scientific, Carlsbad, CA, USA). 
Table 1. Clinicopathological details of patients

\begin{tabular}{|l|c|}
\hline Number of patients & 81 \\
\hline Median follow-up & 53 months \\
\hline Median age & 60 years \\
\hline Median progression-free survival & 21 months \\
\hline Median overall survival & 28 months \\
\hline Tumour & \\
T1 & $41(50.6 \%)$ \\
T2 & $31(38.3 \%)$ \\
T3 & $7(8.6 \%)$ \\
T4 & $2(2.5 \%)$ \\
\hline Node & \\
N0 & $50(61.7 \%)$ \\
N1 & $20(24.7 \%)$ \\
N2 & $7(8.6 \%)$ \\
N3 & $3(3.7 \%)$ \\
Unknown & 1 \\
\hline Metastases & \\
M0 & $81(100 \%)$ \\
M1 & 0 \\
\hline Stage & \\
1 & $34(42 \%)$ \\
2 & $30(37 \%)$ \\
3 & $16(19.8 \%)$ \\
Unknown & 1 \\
\hline Ki67 & \\
Negative $(<20 \%)$ & $16(19.8 \%)$ \\
Positive $\geqslant 20 \%)$ & $63(77.8 \%)$ \\
Unknown & 2 \\
\hline CK5/6 & $37(45.7 \%)$ \\
Negative (<10\%) & $44(54.3 \%)$ \\
Positive ( $\geqslant 10 \%)$ & $55(67.9 \%)$ \\
\hline Chemotherapy after surgery & $24(29.6 \%)$ \\
Yes & 2 \\
No & $59(72.8 \%)$ \\
Unknown & $3.5 \%)$ \\
\hline Radiotherapy after surgery & \\
Yes & \\
Unknown & \\
\hline Abbreviation: CK5/6=cytokeratin5/6. & \\
\hline
\end{tabular}

In vitro 3-dimensional proliferation assay and DNA quantification. A first layer of Matrigel mixed with an equal volume of culture medium without cells was seeded into 48 -well plates (120 $\mu$ l per plate). Cells $\left(10^{4}\right)$ suspended in medium $(100 \mu \mathrm{l})$ were mixed with cold Matrigel $(100 \mu \mathrm{l})$ and seeded on the first Matrigel layer. Cells were grown in DMEM supplemented with $1 \%$ FBS, L-glutamine $\left(2 \mathrm{mmoll}^{-1}\right)$, penicillin $\left(100 \mathrm{U} \mathrm{ml}^{-1}\right)$ and daily treated with EGF $\left(20 \mathrm{ng} \mathrm{ml}^{-1}\right)$. The different drugs used include erlotinib (CP358774; LC Laboratories, Woburn, MA, USA), epirubicin, cyclophosphamide, paclitaxel or cisplatine, which were all kindly provided by the Pharmacology department of CHU. For drug treatment, cells were incubated in Matrigel during $24 \mathrm{~h}$ and the drug was added to the culture medium every 2 days, at the indicated concentrations. After 7 days, cells were recovered from 3D cultures upon treatment with $200 \mu \mathrm{l}$ of Dispase (VWR, Radnor, PA, USA), for $2 \mathrm{~h}$ at $37^{\circ} \mathrm{C}$. After two washes in PBS, cell pellets were diluted in PBS $(1 \mathrm{ml})$ and sonicated. Fluorimetric DNA titration was performed by measuring fluorescence in a Spectra Max Gemini Xs (Molecular Devices, Sunnyvale, CA, USA), at $355 \mathrm{~nm}$ excitation and $460 \mathrm{~nm}$ emission. Results are expressed as percentage of proliferation inhibition of treated cells compared to the untreated cells $(100 \%$ corresponding to a complete proliferation inhibition of treated cells compared to the untreated cells).

In vivo tumourigenicity. The in vivo experiments have been approved by the ethical committee (Comité d'éthique Hospitalo-
Facultaire Universitaire de Liège). Subconfluent cells were trypsinised, suspended in serum-free medium $\left(5 \times 10^{6} \mathrm{cells} \mathrm{ml}^{-1}\right)$, and mixed with an equal volume of cold Matrigel (Chabottaux et al, 2006). Cell suspension $\left(10^{6}\right.$ cells in $\left.400 \mu \mathrm{l}\right)$ was injected subcutaneously into RAG-1 immunodeficient mice at both flanks. Our laboratory has previously reported that the tumour promoting effect of MT4-MMP is similarly observed when tumour cells are injected subcutaneously or in the mammary fat pad (Paye et al, 2014). Tumour growth was assessed by measuring the length and width of tumours every 3-4 days. Tumour volumes were estimated using the formula: length $\times$ width $^{2} \times 0.4$ (Maillard et al, 2005). When the tumour volume reached $200 \mathrm{~mm}^{3}$, mice were randomised into different experimental groups (four mice per group). Mice were intraperitoneally injected with epirubicin $\left(4 \mathrm{mg} \mathrm{kg}^{-1}\right.$, twice a week) and/or orally treated with erlotinib $\left(50 \mathrm{mg} \mathrm{kg}^{-1}\right.$, every day). $\mathrm{NaCl}$ $0.9 \%$ or captisol $6 \%$ was used as vehicles for epirubicin and erlotinib, respectively. When using suboptimal doses of chemotherapeutic agents (six mice per group), mice were treated with $2 \mathrm{mg} \mathrm{kg}^{-1}$ of epirubicin twice a week and/or $50 \mathrm{mg} \mathrm{kg}^{-1}$ of erlotinib every 2 days when the tumour volume reached $100 \mathrm{~mm}^{3}$. In those assays, results are expressed as relative tumour volume: tumour volume measured at a specific time point divided by the tumour volume measured at day 0 , which corresponds to the first day of treatment. The results were presented as the mean of the relative tumour volume for each experimental group with the s.e.m. Statistical significance was evaluated by using the two-way repeated ANOVA.

Flow cytometry. MDA-MB-231 $\left(5 \times 10^{5}\right.$ cells per condition $)$ expressing MT4-MMP-Flag (Truong et al, 2016) or not were treated or not with paclitaxel $(10,50$ or $100 \mathrm{nM})$, epirubicin (100 nM) or erlotinib (100 nM). After $12 \mathrm{~h}$, cells were detached with Accutase, and fixed and permeabilised with the Cytofix/Cytoperm kit (554714; BD Biosciences, San Jose, CA, USA) for 40 min at $4{ }^{\circ} \mathrm{C}$. After washing, cells were incubated with a FITC-conjugated $\mathrm{mAb}$ against Flag M2 (1:500 dilution, F4049; Sigma, St Louis, MO, USA) in $1 \% \mathrm{BSA} / \mathrm{PBS}$, for $1 \mathrm{~h}$ at $4{ }^{\circ} \mathrm{C}$. After washing, cells were analysed by flow cytometry, with 10000 events (FACS Calibur II; $\mathrm{BD}$ Biosciences). For the membrane staining, we followed the same procedure and omitted the fixation and permeabilisation. The median fluorescence intensity of cells treated with paclitaxel was normalised to that of MDA-MB-231 control cells, and compared to untreated cells considered as $100 \%$.

Immunofluorescence and confocal microscopy. MDA-MB-231 cells expressing MT4-MMP were grown on $12 \mathrm{~mm}$ sterile round glass coverslips. After $24 \mathrm{~h}$ of incubation, cells were treated or not with 10,50 or $100 \mathrm{~nm}$ of paclitaxel. After $12 \mathrm{~h}$, cells were fixed for $15 \mathrm{~min}$ in $4 \%$ paraformaldehyde and permeabilised for $5 \mathrm{~min}$ with $0.25 \%$ Triton X-100/PBS, at room temperature. Slides were blocked in PBS containing 1\% BSA and 10\% normal goat serum solution, and incubated with an antibody against MT4-MMP ( $1: 100$ dilution, Ab51075; Abcam) and an antibody against alpha 1 Sodium Potassium ATPase referred as a plasma membrane marker (1/200 dilution, Ab7671; Abcam) in 1\% BSA/PBS overnight at $4{ }^{\circ} \mathrm{C}$. Cells were then incubated with the secondary antibody, that is, Alexa Fluor 546 goat anti-rabbit IgG (1:200 dilution, A11035; Invitrogen) and Alexa Fluor 488 goat anti-mouse IgG (1:1000 dilution, A11029; Invitrogen) in $1 \% \mathrm{BSA} / \mathrm{PBS}$, for $1 \mathrm{~h}$ at $37^{\circ} \mathrm{C}$. Finally, cells were mounted on slides with Dapi Fluoromount-G (0100-20; Southern Biotech, Birmingham, AL, USA) and analysed on an Olympus FV1000 confocal microscope with $\times 60$ oil immersion objective (Olympus America, Waltham, MA, USA).

Statistical analysis. The impact of MT4-MMP and EGFR on the tumour status (T1-2 vs T3-4), the nodal stage (N0-1 vs N2-3) and the Ki67 $(<20 v s \geqslant 20 \%)$ were assessed using univariate and multivariate binary logistic regressions. Results were presented using odds ratios with corresponding 95\% confidence intervals. 
Table 2. Correlation of MT4-MMP and/or EGFR staining in TNBC with clinicopathological parameters using logistic regression and proportional odds model

\begin{tabular}{|c|c|c|c|c|}
\hline \multirow[b]{2}{*}{ Parameters } & \multicolumn{2}{|c|}{ OR $(95 \% \mathrm{Cl})$ crude } & \multicolumn{2}{|c|}{ OR $(95 \% \mathrm{Cl})$ EGFR and MT4-MMP adjusted } \\
\hline & EGFR & MT4-MMP & EGFR & MT4-MMP \\
\hline \multicolumn{5}{|l|}{ Tumours } \\
\hline $\begin{array}{l}\text { T1-T2 } \\
\text { T3-T4 }\end{array}$ & $\begin{array}{c}1.01(0.99-1.03) \\
P=0.41\end{array}$ & $\begin{array}{c}1.01(0.99-1.04) \\
P=0.42\end{array}$ & $\begin{array}{c}1.01(0.99-1.03) \\
P=0.39\end{array}$ & $\begin{array}{c}1.01(0.98-1.04) \\
P=0.43\end{array}$ \\
\hline \multicolumn{5}{|l|}{ Nodes } \\
\hline $\begin{array}{l}\text { N0-N1 } \\
\text { N2-N3 }\end{array}$ & $\begin{array}{c}1.01(0.98-1.03) \\
P=0.62\end{array}$ & $\begin{array}{c}0.97(0.94-1.01) \\
P=0.10\end{array}$ & $\begin{array}{c}1.01(0.98-1.03) \\
P=0.66\end{array}$ & $\begin{array}{c}0.97(0.94-1.01) \\
P=0.094\end{array}$ \\
\hline \multicolumn{5}{|l|}{ Stages } \\
\hline $\begin{array}{l}1 \\
2 \\
3\end{array}$ & $\begin{array}{c}1.00(0.99-1.01) \\
P=0.98\end{array}$ & $\begin{array}{c}0.99(0.98-1.01) \\
P=0.71\end{array}$ & $\begin{array}{c}1.00(0.99-1.01) \\
P=0.97\end{array}$ & $\begin{array}{c}1.00(0.99-1.02) \\
P=0.60\end{array}$ \\
\hline \multicolumn{5}{|l|}{ Ki67 } \\
\hline $\begin{array}{l}<20 \% \\
\geqslant 20 \%\end{array}$ & $\begin{array}{c}1.00(0.99-1.03) \\
P=0.30\end{array}$ & $\begin{array}{c}1.00(0.98-1.02) \\
P=0.91\end{array}$ & $\begin{array}{c}1.00(0.99-1.03) \\
P=0.31\end{array}$ & $\begin{array}{c}0.99(0.98-1.02) \\
P=0.75\end{array}$ \\
\hline
\end{tabular}

Table 3. Multivariate analyses of overall survival and progression-free survival by Cox's proportional hazard model

\begin{tabular}{|c|c|c|c|}
\hline & HR & $95 \% \mathrm{Cl}$ & $P$-value \\
\hline \multicolumn{4}{|l|}{ Complete cohort } \\
\hline $\begin{array}{l}\text { Overall survival } \\
\text { EGFR } \\
\text { MT4-MMP }\end{array}$ & $\begin{array}{l}1.01 \\
0.98\end{array}$ & $\begin{array}{l}0.99-1.03 \\
0.95-1.00\end{array}$ & $\begin{array}{l}0.1848 \\
0.0464^{\star}\end{array}$ \\
\hline $\begin{array}{l}\text { Progression-free survival } \\
\text { EGFR } \\
\text { MT4-MMP }\end{array}$ & $\begin{array}{l}1.03 \\
0.97\end{array}$ & $\begin{array}{l}1.01-1.05 \\
0.94-0.99\end{array}$ & $\begin{array}{l}0.0071^{\star \star} \\
0.0040^{\star \star}\end{array}$ \\
\hline \multicolumn{4}{|c|}{ Patients treated with chemotherapy } \\
\hline $\begin{array}{l}\text { Overall survival } \\
\text { MT4-MMP }\end{array}$ & 0.96 & $0.91-1.01$ & $0.0802^{\star}$ \\
\hline $\begin{array}{l}\text { Progression-free survival } \\
\text { MT4-MMP }\end{array}$ & 0.93 & $0.88-0.98$ & $0.0059 * *$ \\
\hline \multicolumn{4}{|c|}{ Patients untreated with chemotherapy } \\
\hline $\begin{array}{l}\text { Overall survival } \\
\text { MT4-MMP }\end{array}$ & 1.00 & $0.94-1.06$ & 0.9154 \\
\hline $\begin{array}{l}\text { Progression-free survival } \\
\text { MT4-MMP }\end{array}$ & 1.02 & $0.97-1.06$ & 0.5232 \\
\hline
\end{tabular}

The impact of MT4-MMP and EGFR on the stage of the tumour was evaluated using univariate and multivariate proportional odds models (ordinal regression). Cumulative odds ratios and respective 95\% confidence intervals were estimated. Cox's proportional odds models were used to analyse the effect of MT4-MMP and EGFR on the overall survival (OS) and PFS. Additional analyses were applied to determine the impact of MT4-MMP on PFS in patients treated or not with chemotherapy independently. Results were presented using hazard ratios with corresponding $95 \%$ confidence intervals. Those investigations were depicted graphically using KaplanMeier curve. Results were considered to be significant at the 5\% critical level. Analyses were carried out using SAS 9.4 (World Headquarters and SAS Institute Inc., Cary, NC, USA) and GraphPad Prism 5 (GraphPad Software Inc., La Jolla, CA, USA).

\section{RESULTS}

MT4-MMP and EGFR are both overexpressed in the majority of TNBC. Immunohistochemical stainings for MT4-MMP and
EGFR were performed on healthy breast tissues $(n=24)$ and tumour samples issued from the cohort described below. MT4MMP and EGFR expressions were represented by the percentage of cancer cells positive for each immunostaining. Whereas, low MT4MMP and EGFR expression was observed in healthy breast, their expression was increased in TNBC (Figure 1A and B). The different expression patterns (MT4-MMP +/EGFR +, MT4MMP + /EGFR-, MT4-MMP-/EGFR + and MT4-MMP-/EGFR-) are illustrated in Figure 1A. Interestingly, 72.5\% (59 out of 81 ) of TNBC patients expressed MT4-MMP and EGFR together, whereas $25 \%$ (20 out of 81 ) expressed MT4-MMP or EGFR and 2.5\% (2 out of 81 ) were negative for the both proteins. Among the $72.5 \%$ of TNBC patients who expressed MT4-MMP and EGFR, 79\% displayed common stained areas for both proteins in serial section of TNBC (Figure 1C).

TNBC cohort and patient characteristics. Clinical and histological characteristics of patients $(n=81)$ with TNBC are reported in Table 1. The patients who have received neoadjuvant treatment have been excluded from the study. This retrospective cohort consists of women aged from 27 to 89 years diagnosed between February 1999 and September 2013 with a median follow-up of 53 months (4.4 years). During the follow-up, 34 (42\%) patients relapsed or presented progressive disease and 30 (37\%) died. All patients had surgery as the upfront treatment option. Most patients received also adjuvant radiotherapy (59 out of $78,75.6 \%$ ) and chemotherapy (55 out of $79,69.6 \%$ ). The majority of patients receiving adjuvant chemotherapy were treated with the combination of epirubicin and cyclophosphamide associated or not with fluorouracile and/or taxane $(n=45)$. The other patients received CMF (cyclophosphamide methotrexate 5-fluorouracile) $(n=5)$. The majority of patients were clinical stage $1(42.5 \%)$ and 2 (37.5\%), only $20 \%$ of samples were stage 3 . The half of patients (44.7\%) presented lymph node invasion, but no distant metastases were observed. Ki67 expression was at least $20 \%$ in $63(79.7 \%)$ patients. The half of patients (54.3\%) expressed CK5/6, a marker of basal-like tumours.

We next searched for putative association between MT4-MMP and EGFR expressions, and several clinicopathological variables in TNBC patients (Table 2). The statistical analyses were assessed by considering MT4-MMP and EGFR expression as continuous variables without using any arbitrary cut offs. There was no significant association between MT4-MMP or EGFR expression with any of the clinicopathological features evaluated (tumour size, nodal status, stage or Ki67). Similar results were observed 

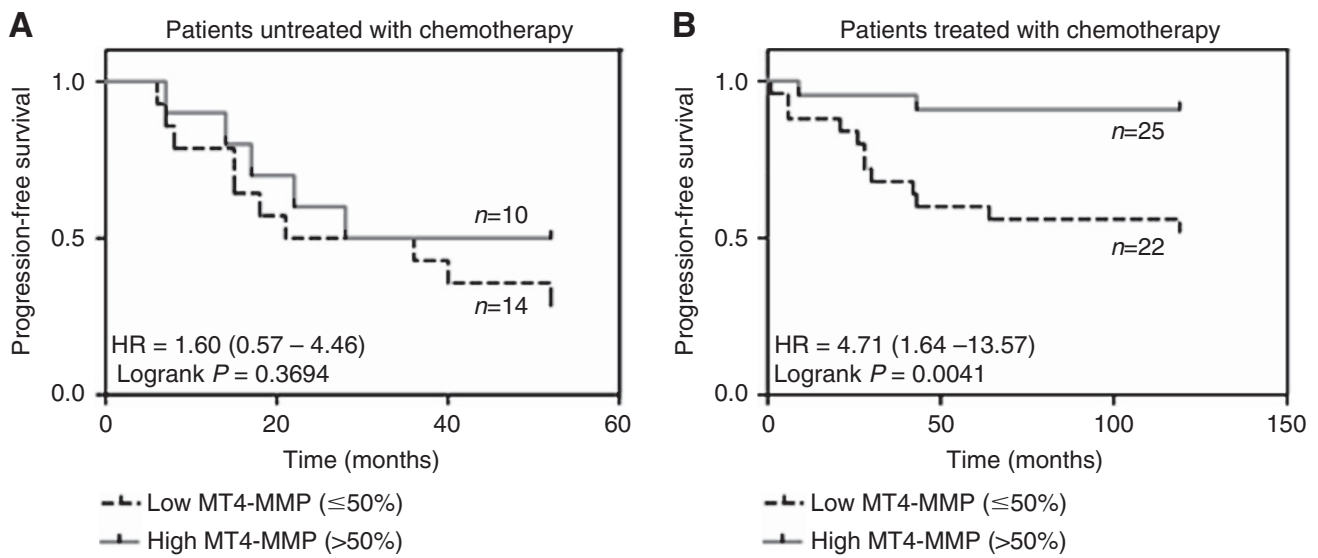

Figure 2. Kaplan-Meier progression-free survival (PFS) curves from patients untreated by chemotherapy $(n=24)$ and TNBC patients treated with chemotherapy $(n=47)$ according the MT4-MMP expression. (A) No significant difference in PFS was observed in patients untreated with chemotherapy. (B) A significant difference in PFS was observed in patients treated with chemotherapy when more than $50 \%$ of breast cancer cells expressed MT4-MMP. Note: $95 \%$ confidence interval is represented between the parentheses. HR, hazard ratio.

when evaluating the impact of MT4-MMP expression by adjusting the EGFR variable, and vice versa (Table 2). In conclusion, MT4-MMP and EGFR were not associated to the tumour size, nodal status, stage or Ki67, whether analysed separately or together.

MT4-MMP expression influences TNBC patients' survival and progression-free survival. In our cohort, EGFR expression is correlated with a poor PFS $(P=0.0071)$ but not with a shorter OS $(P=0.1848)$. Surprisingly, MT4-MMP expression was associated with a significant better OS $(P=0.0464)$ and PFS $(P=0.0040)$ (Table 3). The impact of MT4-MMP on OS and PFS was not highlighted for patients untreated with chemotherapy suggesting that the benefice of MT4-MMP on OS and PFS was linked to the response of patients to chemotherapy (Table 3). Indeed, in the cohort of patients treated with chemotherapy, MT4-MMP was still linked to a better OS $(P=0.0802)$ and PFS $(P=0.0059)$. The impact of MT4-MMP expression on PFS in patients treated or not with chemotherapy is illustrated by the Kaplan-Meier curves applying a cut off of $50 \%$, which corresponded to the cut off from which a significant impact of MT4-MMP on PFS was observed (Figure 2).

MT4-MMP expression sensitises TNBC cells to chemotherapies in vitro. Our clinical data prompted us to conduct an in vitro study to assess whether MT4-MMP expression could influence the response of TNBC cells to chemotherapeutic agents. The proliferation rate of TNBC MDA-MB-231 cells overexpressing MT4-MMP (MT4-MMP cells) or not (CTRL cells) was evaluated in a $3 \mathrm{D}$-matrigel assay to better mimic the in vivo situation, as previously described (Paye et al, 2014). Cells were treated with increasing concentrations of different chemotherapeutic agents. Four chemotherapeutic agents currently used in the clinic were evaluated: epirubicin, cyclophosphamide, cisplatin and paclitaxel. Interestingly, the overexpression of MT4-MMP conferred a therapeutic benefit to epirubicin, cyclophosphamide and cisplatin (Figure 3A-C). Indeed, the proliferation of MDA-MB-231 cells overexpressing MT4-MMP was more affected in the presence of these drugs compared to control cells. A higher cell proliferation inhibition was achieved with MDA-MB-231 overexpressing MT4MMP than non-expressing cells: 6.5 -fold for epirubicin at $1 \mu \mathrm{M}$, 13.5-fold for cyclophosphamide at $0.01 \mathrm{~mm}$ and 1.5 -fold for cisplatin at $0.1 \mu \mathrm{M}$. Surprisingly, MDA-MB-231 cells overexpressing MT4-MMP did not show any additional therapeutic benefit to paclitaxel. Cancer cell response to paclitaxel was similar in MDAMB-231 overexpressing MT4-MMP or not (Figure 3E). Paclitaxel inhibits microtubule depolymerisation and has been described to affect the secretion and the activity of MMP-2 and MMP-9 (Schnaeker et al, 2004). Accordingly, we found that MT4-MMP trafficking was disturbed upon paclitaxel treatment. Proportionally to paclitaxel doses, the amount of MT4-MMP present at the cell membrane was decreased and the enzymes accumulated in the cytoplasm. The loss of MT4-MMP at the membrane and its accumulation in the cytoplasm was confirmed by a confocal microscopy analysis of MT4-MMP and alpha 1 NaK-ATPase, referred as a plasma membrane marker (Oldridge et al, 2013; Figure 3F). A reduced availability of MT4-MMP at the cell surface induced by paclitaxel could reduce its interaction with EGFR abolishing, thereby its proliferative effect of MT4-MMP and cell sensitisation to paclitaxel. In reverse, the MT4-MMP at the membrane and the total MT4-MMP was not disturbed by epirubicin (Figure 3G). All together, we concluded that MT4MMP expression sensitises TNBC cells in vitro to epirubicin, cyclophosphamide and cisplatin, but not to paclitaxel.

MT4-MMP expression sensitises TNBC cells to erlotinib in vitro. Although EGFR overexpression is observed in more than $50 \%$ of TNBC, its inhibition alone or in combination with chemotherapy has resulted in minimal clinical benefit. Therefore, it is crucial to identify a biomarker to select TNBC patients susceptible to respond to anti-EGFR treatment. Accordingly, we extended our work to erlotinib, a TKI. In the 3D-matrigel assay, the proliferation of MDA-MB-231 overexpressing MT4-MMP was more affected by erlotinib than that of control cells (Figure 3D). At $1 \mu \mathrm{M}$ of erlotinib, the inhibition of cell proliferation was twice higher in the presence of MT4-MMP expression $(P<0.01)$. The MT4-MMP at the membrane and the total MT4-MMP was not disturbed by erlotinib or the combination of erlotinib and epirubicin (Figure 3G).

MT4-MMP expression sensitises TNBC xenografts to epirubicin and erlotinib. To validate the in vitro findings, we next tested the impact of MT4-MMP expression on in vivo response of tumours to a chemotherapeutic agent (epirubicin) and erlotinib, in monotherapies and in combination treatments. As previously described, MT4-MMP xenografts grew faster than control xenografts (Figure 4A). Mice bearing xenograft of MDA-MB-231 cells overexpressing or not MT4-MMP were treated with $4 \mathrm{mg} \mathrm{kg}^{-1}$ of epirubicin twice a week, $50 \mathrm{mg} \mathrm{kg}^{-1}$ of erlotinib once a day or with the combination of the two treatments. Upon epirubicin or erlotinib treatment, the growth of MT4-MMP tumour was stabilised (Figure 4B). In sharp contrast, the growth of control 

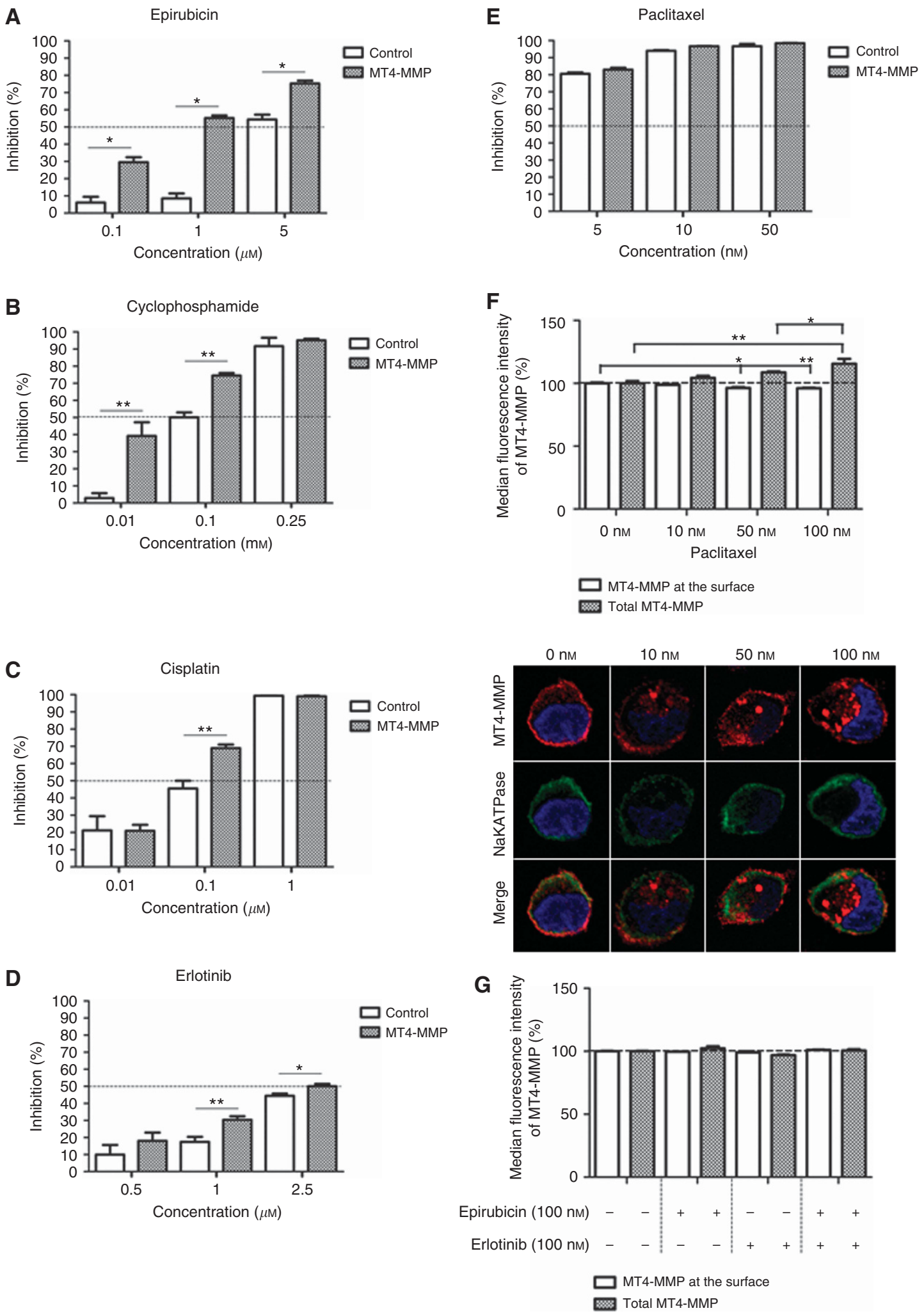

Figure 3. MT4-MMP overexpression sensitises MDA-MB-231 cells to alkylating and intercalating chemotherapies, and erlotinib but not to paclitaxel. MDA-MB-231 cells overexpressing MT4-MMP (MT4-MMP) or not (control) were incubated in a 3D matrix (Matrigel). Cell proliferation was assessed by DNA measurement after 7 days of culture in the presence of different concentrations of epirubicin (A), cyclophosphamide (B), cisplatin (C), erlotinib (D) and paclitaxel (E) as indicated. Results are expressed as percentage of inhibition. (F) Paclitaxel disturbs the intracellular trafficking of MT4-MMP. FACS analysis demonstrated that MT4-MMP was decreased at the cell surface and accumulated in the cytoplasm (total MT4-MMP). A representative illustration of MT4-MMP (in red) and NaK-ATPase (green) stainings observed by confocal microscopy is shown below the graph, for each paclitaxel concentration used. The blue staining corresponds to the nucleus stained with Dapi Fluoromount-G. (G) The intracellular trafficking of MT4-MMP was not disturbed by the treatment of epirubicin or erlotinib or the combination. FACS analysis demonstrated that the total MT4-MMP and the MT4-MMP at the membrane was not modified by these drugs. ${ }^{\star} P<0.05 ;{ }^{\star \star} P<0.01$. 
A
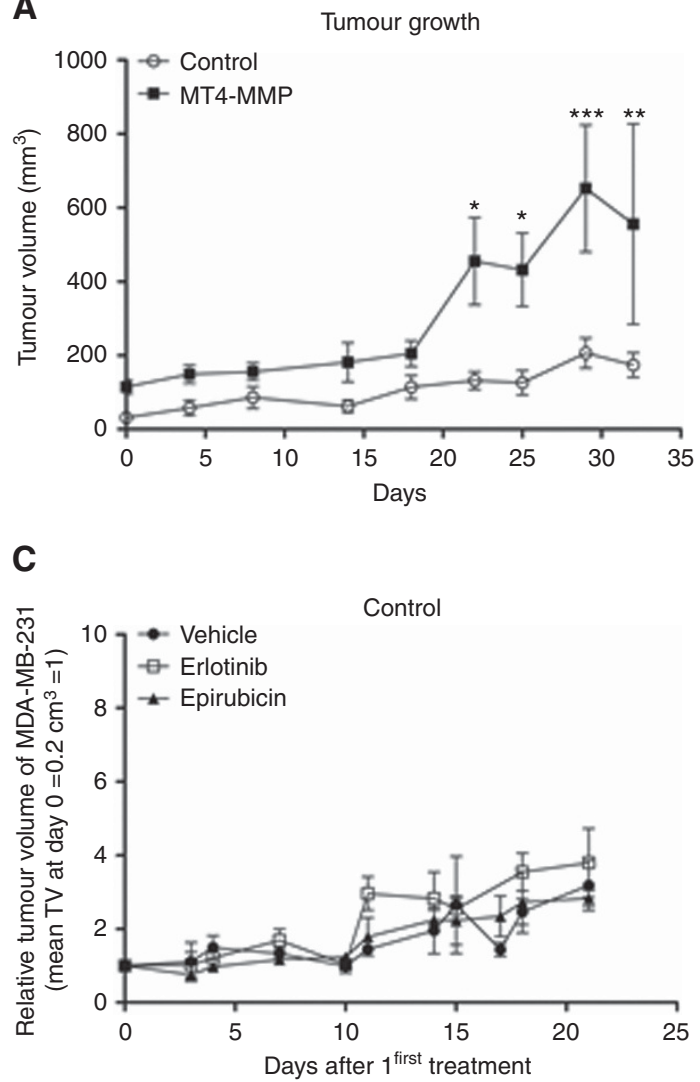

B

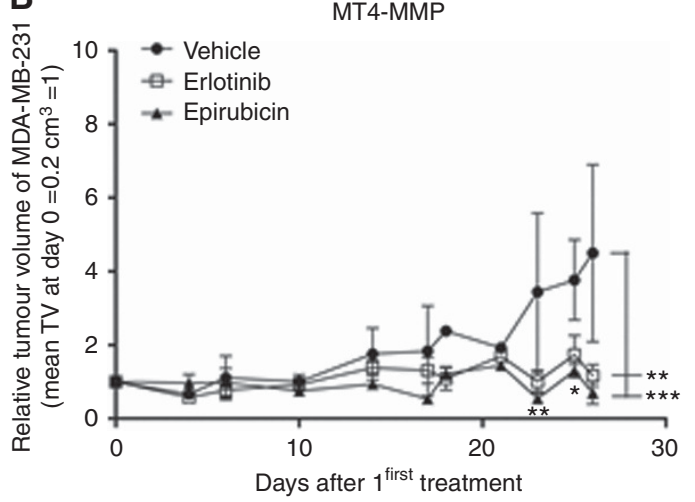

D

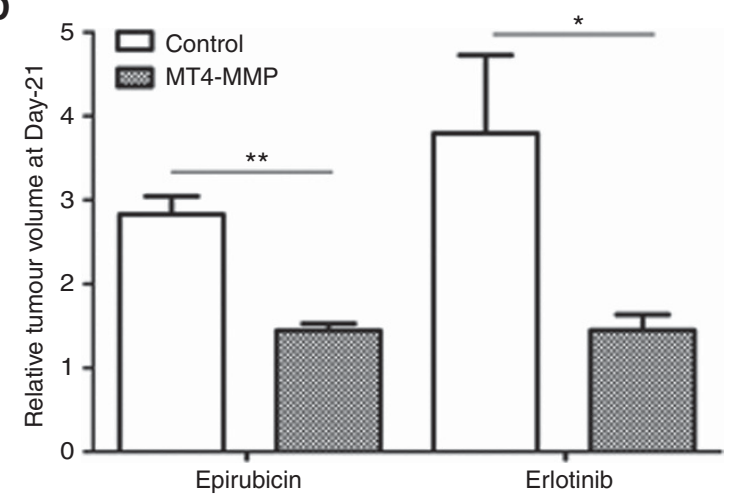

Figure 4. MT4-MMP overexpression sensitises MDA-MB-231 xenografts to epirubicin and erlotinib. (A) Tumour growth of MDA-MB-231 cells overexpressing or not MT4-MMP injected in RAG-1 immunodeficient mice. (B, C) Relative tumour growth of MDA-MB-231 xenografts overexpressing (B) or not (C) MT4-MMP treated with vehicle $(n=4)$, epirubicin $(n=4)$ or erlotinib $(n=4)$. Mice were intraperitoneally injected with epirubicin $\left(4 \mathrm{mg} \mathrm{kg}^{-1}\right)$ twice a week or orally treated with erlotinib $\left(50 \mathrm{mg} \mathrm{kg}^{-1}\right)$ once a day. $\mathrm{NaCl} 0.9 \%$ and captisol $6 \%$ were used as control for epirubicin and erlotinib, respectively. Tumour volume was measured twice a week. (D) Comparison of the relative tumour growth of control and MT4-MMP tumours treated with epirubicin or erlotinib at the end of the assay (day 21). Values are means \pm s.e.m. ${ }^{\star} P<0.05 ;{ }^{\star \star} P<0.01$;

$\star \star \star P<0.001$

xenografts was not affected by epirubicin or erlotinib and was similar to that of tumour treated with the vehicle (Figure 4C). In line with in vitro data, MT4-MMP tumours were thus more sensitive to epirubicin and erlotinib monotherapies (Figure 4D). Due to a high toxicity of epirubicin and erlotinib combination leading to mice death, we next used suboptimal doses of epirubicin and erlotinib. In those conditions, no effect of the monotherapy was observed on the tumour growth of MT4-MMP or control xenografts. Interestingly, the combination of epirubicin and erlotinib treatments led to a drastic inhibition of the growth of MT4-MMP xenografts, but did not affect the progression of control tumours (Figure 5A and B). The comparison of the tumour volume reached at the end of the assay (Figure 5C) revealed a clear improved response to drug combination by MT4-MMP expressing xenografts as compared to control tumours, as well as to monotherapies. Membrane type- 4 matrix metalloproteinase expression endows to the tumour with a higher sensitivity to erlotinib combined with epirubicin.

\section{DISCUSSION}

We here established an unprecedented link between a strong MT4-MMP expression and an increased PFS in patients treated by chemotherapy. We identified MT4-MMP as a marker of tumour response to alkylating or intercalating agents used in monochemotherapy, or combined with erlotinib. This is supported by (1) clinical data using a retrospective cohort of TNBC patients subjected or not to chemotherapy; (2) in vitro data in a 3D model demonstrating a higher sensitivity of TNBC cells to DNA-targeting drugs, but not to a cytoskeletal-targeting drug and finally (3) preclinical data in TNBC xenografts demonstrating the efficacy of a combination of suboptimal doses of DNA-interfering drug and erlotinib to completely block tumour growth.

Human MT4-MMP is a pro-tumoural protein expressed by cancer cells that promotes metastatic dissemination through its catalytic function (Host et al, 2012) and tumour cell proliferation by interfering with EGFR (Chabottaux et al, 2006; Paye et al, 2014). We found that MT4-MMP and EGFR were overexpressed in $>70 \%$ of TNBC samples. In line with the literature, EGFR expression was not associated with clinicopathological factors (tumour size, lymph node invasion, tumour stage or Ki67; Rao et al, 2013; Sood and Nigam, 2014), but was linked to a poor PFS (Viale et al, 2009). Although MT4-MMP was not associated to clinicopathological features, its expression and co-localisation with EGFR in $79 \%$ of TNBC patients might affect patient outcome and response to chemotherapy. Indeed, patients developing tumours with more than 50\% of MT4-MMP-positive cells showed a better PFS when treated with chemotherapy. In contrast, MT4-MMP expression was not associated to PFS in untreated patients. Given the reported mitogenic effect of this protease (Chabottaux et al, 2006; Paye et al, 2014), MT4-MMP overexpression in TNBC cells could make them more sensitive to DNA-targeting agents. This concept is supported by our data showing increased TNBC cell responsiveness to alkylating (cyclophosphamide, cisplatin) or intercalating (epirubicin) agents, but not to paclitaxel. The lack 

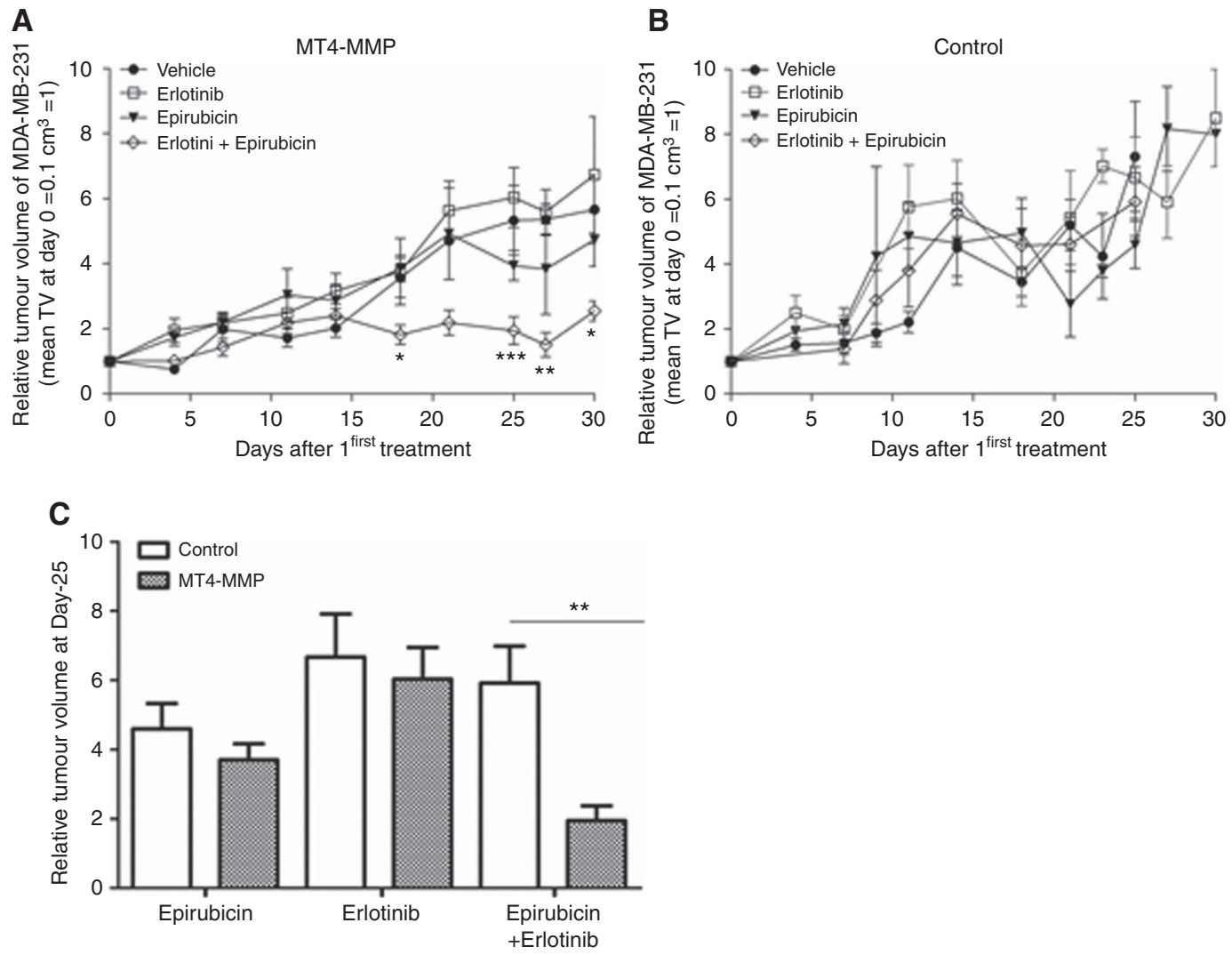

Figure 5. MT4-MMP overexpression sensitises MDA-MB-231 xenografts to a combination of epirubicin and erlotinib. (A, B) Relative tumour growth of MDA-MB-231 xenografts overexpressing or not MT4-MMP treated with vehicle $(n=6)$, epirubicin $(n=6)$, erlotinib $(n=6)$ or a combination of the two drugs $(n=6)$. Mice were intraperitoneally injected with epirubicin $\left(2 \mathrm{mg} \mathrm{kg}^{-1}\right)$ twice a week and/or were orally treated with erlotinib $\left(50 \mathrm{mg} \mathrm{kg}^{-1}\right)$ three times a week. (C) Comparison of relative tumour growth of control and MT4-MMP tumours treated with epirubicin and/or erlotinib at day 25. Values are means \pm s.e.m. ${ }^{\star} P<0.05 ;{ }^{*} P<0.01 ;{ }^{* \star} P<0.001$.

of response to paclitaxel could be ascribed to the impact of microtubule disruption on MT4-MMP availability at the cell surface. Indeed, MT4-MMP internalisation dynamics was recently reported showing that the enzyme stays $45 \mathrm{~min}$ at the cell surface before being internalised and either auto-degraded or recycled to the cell surface (Truong et al, 2016). It is thus not surprising that compounds that can affect its trafficking and internalisation dynamics could also affect its interaction with EGFR, and hamper its impact on cell proliferation.

Despite a good initial response of TNBC to chemotherapy, metastatic relapse occurs at higher rates compared to other breast cancer subtypes (Isakoff, 2010; O'Reilly et al, 2015). Epidermal growth factor receptor overexpression by most TNBC offers an opportunity that could be explored for an effective targeted therapy. However, up to now, clinical trials using anti-EGFR antibodies in TNBC patients did not show any benefit in terms of PFS. These disappointing results with cetuximab could be explained, at least partly, by the contribution of compensatory pathways of TK signalling, and/or of unknown factors interfering with the EGFR pathway. Here we provide in vivo evidence of effective response of MT4-MMP and EGFR expressing tumours to erlotinib. Membrane type-4 matrix metalloproteinase expression conferred to xenografts, a better response to epirubicin and erlotinib alone (monotherapy) and more importantly, to the combination of these drugs at suboptimal doses. This is in line with our previous in vitro data showing that erlotinib blocked drastically the proliferation of MT4-MMP expressing cells in 3D cultures. In contrast, only a partial inhibition of cell proliferation was achieved with cetuximab. Thus, MT4-MMP endows tumour cells with a higher sensitivity to TKIs that act intracellularly than to antibodies exerting an extracellular effect. This could explain why cetuximab treatment was inefficient to treat TNBC patients despite the presence of MT4-MMP. These innovative findings hold promise for the use of TKI in selected TNBC overexpressing MT4-MMP.

Altogether, these findings provide the first clinical and molecular evidence for MT4-MMP role in TNBC. These innovative findings hold promise for the use of TKI (erlotinib) combined with DNAinterfering chemotherapeutic agents in selected TNBC overexpressing MT4-MMP and EGFR. The MT4-MMP/EGFR axis emerges as a new valuable pathway that could have a striking impact on TNBC cancer patients expressing these two molecules.

\section{ACKNOWLEDGEMENTS}

This work was supported by grants from the Plan Cancer, the Fonds de la Recherche Scientifique FRS-FNRS, the Fondation Contre le Cancer, the Interuniversity Attraction Poles Programme - Belgian Science Policy, the Centre Anticancereux (CAC), the Fonds Leon Fredericq and Fonds speciaux of the University of Liege, Belgium. We thank the platforms of the Groupe Interdisciplinaire de Genoproteomique Appliquee (GIGA) (Imaging GIGA platform, Immunohistology GIGA Platform and the Biothèque-University of Liège). We are grateful to Marie Dehuy and Isabelle Dasoul for their technical support. Cassandre Yip and Mehdi Lienard are recipients of FNRS-Télevie grants. Pierre Foidart and Alice Truong are supported by FNRS.

\section{CONFLICT OF INTEREST}

The authors declare no conflict of interest. 


\section{REFERENCES}

Baselga J, Gomez P, Greil R, Braga S, Climent MA, Wardley AM, Kaufman B, Stemmer SM, Pego A, Chan A, Goeminne JC, Graas MP, Kennedy MJ, Ciruelos Gil EM, Schneeweiss A, Zubel A, Groos J, Melezinkova H, Awada A (2013) Randomized phase II study of the anti-epidermal growth factor receptor monoclonal antibody cetuximab with cisplatin versus cisplatin alone in patients with metastatic triple-negative breast cancer. J Clin Oncol 31: 2586-2592.

Bauer KR, Brown M, Cress RD, Parise CA, Caggiano V (2007) Descriptive analysis of estrogen receptor (ER)-negative, progesterone receptor (PR)negative, and HER2-negative invasive breast cancer, the so-called triplenegative phenotype: a population-based study from the California cancer Registry. Cancer 109: 1721-1728.

Bertucci F, Finetti P, Cervera N, Esterni B, Hermitte F, Viens P, Birnbaum D (2008) How basal are triple-negative breast cancers? Int J Cancer 123: 236-240.

Carey L, Winer E, Viale G, Cameron D, Gianni L (2010) Triple-negative breast cancer: disease entity or title of convenience? Nat Rev Clin Oncol 7: 683-692.

Carey LA, Perou CM, Livasy CA, Dressler LG, Cowan D, Conway K, Karaca G, Troester MA, Tse CK, Edmiston S, Deming SL, Geradts J, Cheang MC, Nielsen TO, Moorman PG, Earp HS, Millikan RC (2006) Race, breast cancer subtypes, and survival in the Carolina Breast Cancer Study. JAMA 295: 2492-2502.

Carey LA, Rugo HS, Marcom PK, Mayer EL, Esteva FJ, Ma CX, Liu MC, Storniolo AM, Rimawi MF, Forero-Torres A, Wolff AC, Hobday TJ, Ivanova A, Chiu WK, Ferraro M, Burrows E, Bernard PS, Hoadley KA, Perou CM, Winer EP (2012) TBCRC 001: randomized phase II study of cetuximab in combination with carboplatin in stage IV triple-negative breast cancer. J Clin Oncol 30: 2615-2623.

Chabottaux V, Ricaud S, Host L, Blacher S, Paye A, Thiry M, Garofalakis A, Pestourie C, Gombert K, Bruyere F, Lewandowsky D, Tavitian B, Foidart JM, Duconge F, Noel A (2009) Membrane-type 4 matrix metalloproteinase (MT4-MMP) induces lung metastasis by alteration of primary breast tumour vascular architecture. J Cell Mol Med 13: 4002-4013.

Chabottaux V, Sounni NE, Pennington CJ, English WR, Den Brule VAN, Blacher F, Gilles S, Munaut C, Maquoi C, Lopez-Otin E, Murphy C, Edwards G, Foidart DR, Noel A JM (2006) Membrane-type 4 matrix metalloproteinase promotes breast cancer growth and metastases. Cancer Res 66: 5165-5172.

Collignon J, Lousberg L, Schroeder H, Jerusalem G (2016) Triple-negative breast cancer: treatment challenges and solutions. Breast Cancer (Dove Med Press) 8: 93-107.

Finn RS, Bengala C, Ibrahim N, Roche H, Sparano J, Strauss LC, Fairchild J, Sy O, Goldstein LJ (2011) Dasatinib as a single agent in triple-negative breast cancer: results of an open-label phase 2 study. Clin Cancer Res 17: 6905-6913.

Gazinska P, Grigoriadis A, Brown JP, Millis RR, Mera A, Gillett CE, Holmberg LH, Tutt AN, Pinder SE (2013) Comparison of basal-like triplenegative breast cancer defined by morphology, immunohistochemistry and transcriptional profiles. Mod Pathol 26: 955-966.

Herschkowitz JI, Simin K, Weigman VJ, Mikaelian I, Usary J, Hu Z, Rasmussen KE, Jones LP, Assefnia S, Chandrasekharan S, Backlund MG, Yin Y, Khramtsov AI, Bastein R, Quackenbush J, Glazer RI, Brown PH, Green JE, Kopelovich L, Furth PA, Palazzo JP, Olopade OI, Bernard PS, Churchill GA, Van Dyke T, Perou CM (2007) Identification of conserved gene expression features between murine mammary carcinoma models and human breast tumors. Genome Biol 8: R76.

Host L, Paye A, Detry B, Blacher S, Munaut C, Foidart JM, Seiki M, Sounni NE, Noel A (2012) The proteolytic activity of MT4-MMP is required for its pro-angiogenic and pro-metastatic promoting effects. Int $J$ Cancer 131: 1537-1548.

Huang CH, Yang WH, Chang SY, Tai SK, Tzeng CH, Kao JY, Wu KJ, Yang MH (2009) Regulation of membrane-type 4 matrix metalloproteinase by SLUG contributes to hypoxia-mediated metastasis. Neoplasia 11: 1371-1382.

Huang L, Liu Z, Chen S, Liu Y, Shao Z (2013) A prognostic model for triplenegative breast cancer patients based on node status, cathepsin-D and Ki-67 index. PLoS One 8: e83081.

Isakoff SJ (2010) Triple-negative breast cancer: role of specific chemotherapy agents. Cancer J 16: 53-61.

Kessenbrock K, Plaks V, Werb Z (2010) Matrix metalloproteinases: regulators of the tumor microenvironment. Cell 141: 52-67.
Layman RM, Ruppert AS, Lynn M, Mrozek E, Ramaswamy B, Lustberg MB, Wesolowski R, Ottman S, Carothers S, Bingman A, Reinbolt R, Kraut EH, Shapiro CL (2013) Severe and prolonged lymphopenia observed in patients treated with bendamustine and erlotinib for metastatic triple negative breast cancer. Cancer Chemother Pharmacol 71: 1183-1190.

Maillard C, Jost M, Romer MU, Brunner N, Houard X, Lejeune A, Munaut C, Bajou K, Melen L, Dano K, Carmeliet P, Fusenig NE, Foidart JM, Noel A (2005) Host plasminogen activator inhibitor-1 promotes human skin carcinoma progression in a stage-dependent manner. Neoplasia 7: 57-66.

Nanda R, Chow LQ, Dees EC, Berger R, Gupta S, Geva R, Pusztai L, Pathiraja K, Aktan G, Cheng JD, Karantza V, Buisseret L (2016) Pembrolizumab in patients with advanced triple-negative breast cancer: phase Ib KEYNOTE012 Study. J Clin Oncol 34: 2460-2467.

Noel A, Gutierrez-Fernandez A, Sounni NE, Behrendt N, Maquoi E, Lund IK, Cal S, Hoyer-Hansen G, Lopez-Otin C (2012) New and paradoxical roles of matrix metalloproteinases in the tumor microenvironment. Front Pharmacol 3: 140.

O’Reilly EA, Gubbins L, Sharma S, Tully R, Guang MH, Weiner-Gorzel K, Mccaffrey J, Harrison M, Furlong F, Kell M, Mccann A (2015) The fate of chemoresistance in triple negative breast cancer (TNBC). BBA Clin 3: 257-275.

Oldridge EE, Walker HF, Stower MJ, Simms MS, Mann VM, Collins AT, Pellacani D, Maitland NJ (2013) Retinoic acid represses invasion and stem cell phenotype by induction of the metastasis suppressors RARRES1 and LXN. Oncogenesis 2: e45.

Paye A, Truong A, Yip C, Cimino J, Blacher S, Munaut C, Cataldo D, Foidart JM, Maquoi E, Collignon J, Delvenne P, Jerusalem G, Noel A, Sounni NE (2014) EGFR activation and signaling in cancer cells are enhanced by the membranebound metalloprotease MT4-MMP. Cancer Res 74: 6758-6770.

Perou CM, Sorlie T, Eisen MB, Van de Rijn M, Jeffrey SS, Rees CA, Pollack JR, Ross DT, Johnsen H, Akslen LA, Fluge O, Pergamenschikov A, Williams C, Zhu SX, Lonning PE, Borresen-Dale AL, Brown PO, Botstein D (2000) Molecular portraits of human breast tumours. Nature 406: 747-752.

Rao C, Shetty J, Prasad KH (2013) Immunohistochemical profile and morphology in triple-negative breast cancers. J Clin Diagn Res 7: 1361-1365.

Schnaeker EM, Ossig R, Ludwig T, Dreier R, Oberleithner H, Wilhelmi M, Schneider SW (2004) Microtubule-dependent matrix metalloproteinase-2/ matrix metalloproteinase- 9 exocytosis: prerequisite in human melanoma cell invasion. Cancer Res 64: 8924-8931.

Sood N, Nigam JS (2014) Correlation of CK5 and EGFR with clinicopathological profile of triple-negative breast cancer. Patholog Res Int 2014: 141864.

Sorlie T, Perou CM, Tibshirani R, Aas T, Geisler S, Johnsen H, Hastie T, Eisen MB, Van de Rijn M, Jeffrey SS, Thorsen T, Quist H, Matese JC, Brown PO, Botstein D, Lonning PE, Borresen-Dale AL (2001) Gene expression patterns of breast carcinomas distinguish tumor subclasses with clinical implications. Proc Natl Acad Sci USA 98: 10869-10874.

Teng YH, Tan WJ, Thike AA, Cheok PY, Tse GM, Wong NS, Yip GW, Bay BH, Tan PH (2011) Mutations in the epidermal growth factor receptor (EGFR) gene in triple negative breast cancer: possible implications for targeted therapy. Breast Cancer Res 13: R35.

Torre LA, Bray F, Siegel RL, Ferlay J, Lortet-Tieulent J, Jemal A (2015) Global cancer statistics, 2012. CA Cancer J Clin 65: 87-108.

Truong A, Yip C, Paye A, Blacher S, Munaut C, Deroanne C, Noel A, Sounni NE (2016) Dynamics of internalization and recycling of the prometastatic membrane type 4 matrix metalloproteinase (MT4-MMP) in breast cancer cells. Febs J 283: 704-722.

Viale G, Rotmensz N, Maisonneuve P, Bottiglieri L, Montagna E, Luini A, Veronesi P, Intra M, Torrisi R, Cardillo A, Campagnoli E, Goldhirsch A, Colleoni M (2009) Invasive ductal carcinoma of the breast with the 'triplenegative' phenotype: prognostic implications of EGFR immunoreactivity. Breast Cancer Res Treat 116: 317-328.

Wang Y, Yu SJ, Li YX, Luo HS (2015) Expression and clinical significance of matrix metalloproteinase-17 and -25 in gastric cancer. Oncol Lett 9: 671-676.

Yadav BS, Sharma SC, Chanana P, Jhamb S (2014) Systemic treatment strategies for triple-negative breast cancer. World J Clin Oncol 5: 125-133.

This work is published under the standard license to publish agreement. After 12 months the work will become freely available and the license terms will switch to a Creative Commons AttributionNonCommercial-Share Alike 4.0 Unported License. 